\title{
Design and experiment on atomizer parameter of impinging low-speed centrifugal atomization sprayer
}

\author{
Dejiang Liu, Yan Gong*, Xiao Chen, Xiao Zhang, Guo Wang \\ (Nanjing Institute of Agricultural Mechanization, Ministry of Agriculture and Rural Affairs, Nanjing 210014, China)
}

\begin{abstract}
Atomizers were designed with different atomization parameters to obtain droplets that satisfy optimal particle size requirements for an impinging-type low-speed centrifugal atomizing sprayer. The main factors affecting droplet size are turntable speed, the number of teeth and the tooth shape of the toothed disc. Winner318 software was used to evaluate droplet sizes for different structures and the working parameters of the atomizer. The response surface method and Design-Expert were used to analyze the effect of each factor. The response surface analysis of the effect of structural and working parameters of the atomizer on the interaction between the volume medium diameter of the droplet and the spectral width of the droplet size was used to establish the atomizer droplet Granular spectrum prediction model. Optimal design fitting formulas are obtained, and the droplet sizes required for pesticides to control flying insect pests, to control the growth of reptile larvae, and the use of spraying fungicides to prevent crop damage were determined. This research provides a product not only similar to those in the market, but also the theoretical basis and references for innovation, development, and optimization of centrifugal atomization technology.
\end{abstract}

Keywords: centrifugal atomization, impinging low-speed, droplets diameter, optimal biological particle size theory, quadratic regression analysis

DOI: $10.25165 /$ j.ijabe.20201306.5617

Citation: Liu D J, Gong Y, Chen X, Zhang X, Wang G. Design and experiment on atomizer parameter of impinging low-speed centrifugal atomization sprayer. Int J Agric \& Biol Eng, 2020; 13(6): 118-124.

\section{Introduction}

The "biological optimal particle size" theory states that the particle size range of droplets suitable for capturing different biological targets is different, and the possibility of a medical solution interacting with a biological target directly affects the effective utilization and control of pesticides. A large number of experimental studies showed that the optimal droplet size ranges between $50-150 \mu \mathrm{m}$ when spraying fungicides, and it is $250 \mu \mathrm{m}$ when spraying herbicides ${ }^{[1-3]}$. Therefore, accurately controlling the size of the droplets when employing plant protection machinery and obtaining a narrow spectrum of the droplets is effective to ensure efficient pest control and minimize pesticide pollution. Traditional chemical liquid atomization technologies such as hydraulic atomization and pneumatic atomization involve a wide spectrum of particle sizes and a large number of invalid droplets, thereby causing a large number of small droplets to drift, and large droplets to be lost, which decreases the effective utilization rate of the pesticide ${ }^{[1,2]}$.

\section{Received date: 2019-12-17 Accepted date: 2020-05-03}

Biographies: Dejiang Liu, MS, Assistant Researcher, research interests: equipment for crop protection and pesticide application technology, Email: liudejiang@caas.cn; Xiao Chen, MS, Assistant Researcher, research, interests: equipment for crop protection and pesticide application technology, Email: 1205787558@qq.com; Xiao Zhang, MS, Assistant Researcher, research interests: equipment for crop protection and pesticide application technology, Email: zhangxiao_xhx@126.com; Guo Wang, MS, Assistant Researcher, research interests: equipment for crop protection and pesticide application technology, Email: 512829304@qq.com.

*Corresponding author: Yan Gong, $\mathrm{PhD}$, Professor, research interests: equipment for crop protection and pesticide application technology. Nanjing Research Institute for Agricultural Mechanization, Ministry of Agriculture and Rural Affairs, Nanjing 210014, China. Tel: +86-25-84346241, Email: jsgymm@hotmail.com.
Therefore, an ideal control effect cannot be achieved, which can lead to serious environmental pollution.

Controllable droplet application (CDA) technology is a low-volume spraying technology adopted by developed countries $^{[2-4]}$. Further, centrifugal atomization technology is currently recognized globally as an advanced technology that produces uniform fine droplets within a narrow particle spectrum range ${ }^{[3]}$. In the 1950s, some countries in Western Europe conducted experiments in Africa to employ centrifugal atomization technology to the aerial application of ultra-low-volume spraying $^{[3-8]}$. The earliest designed centrifugal atomizing turntable has no teeth on the edge. In 1970, Bals, the founder of the "Controllable Fog Drop" theory, designed an edged-toothed

turntable to form a semi-shuttle cone-shaped fog ejection point to reduce the force required to generate tension for producing smaller droplets ${ }^{[9-12]}$. Further, Bals invented a turntable with a groove on the inner surface in 1976. This helped create a uniformly flowing groove that allowed liquid drugs to be broken down into liquid filaments before reaching the edge of both grooved and pointed turntables. The toothed turntable produces droplets in a very narrow particle spectrum range, and therefore, it can be used for "controllable mist droplet" plant protection equipment ${ }^{[13-15]}$.

In recent years, there has been a considerable increase in new plant protection equipment products that employ centrifugal atomization technology as the core technology, and these products have been widely used in aviation plant protection and ground micro spraying fields ${ }^{[16-19]}$. The key component of the Micronair AU3000, AU4000, AU5000, and other series products (Micron group, UK) in the field of aviation spray is an air-cylinder rotating nozzle driven by airflow to rotate at high speed. Under the action of centrifugal force, this nozzle can eject tiny droplets below $30 \mu \mathrm{m}$ at high speed above $8000 \mathrm{r} / \mathrm{min}$. 
The development of centrifugal spray technology in China started late; however, related research has been conducted since the 1970s. In 1974, the Dongfanghong-18 type power sprayer was developed for low-volume spraying, which is used in agricultural pest control and sanitary and epidemic prevention. It uses a high-speed airflow generated by a centrifugal fan to rotate the teethed turntable at $9000 \mathrm{r} / \mathrm{min}$. Because it rotates at a high speed, the 180 tooth tips on the outer periphery of the front and rear teeth of the medicinal liquid are ejected at linear speeds of $135 \mathrm{~m} / \mathrm{s}$ and atomized into 15-75 $\mu \mathrm{m}$ diameter droplets ${ }^{[20-22]}$. This device can control droplet size based on the rotation speed of the turntable. In the same year, centrifugal atomization technology was also employed in aerial applications of ultra-low-volume spraying ${ }^{[23]}$.

This study aimed to derive an optimal design fitting formula for an impinging-type low-speed centrifugal atomizer to determine the optimal combination of the structural parameters and working parameters of the atomizer satisfying the "biological optimal particle size" theory. The impinging-type low-speed centrifugal atomizing sprayer was designed, and orthogonal test analysis of the droplet spectrum of the atomizer under different structural parameters was conducted; The study result was expected to provide a theoretical basis and a reference for future research. The paper is divided into three parts, the first part introduces the design of basic and key components of impact-type low-speed centrifugal atomizing sprayer, the second part introduces the orthogonal test analysis of droplet spectrum under different structural parameters, and the third part introduces conclusions.

\section{Design of basic and key components of impact-type low-speed centrifugal atomizing sprayer}

\subsection{Structure}

An impact-type low-speed centrifugal atomizing sprayer is composed of a power system, speed-regulating device, liquid-supply system, wind-assist system, spray tank, machine frame, control system, and centrifugal atomizer. Considering the convenience of using and moving the machine, a four-wheeled walking cart structure of the locking device is employed for moving and operating the machine. An air cylinder is placed above the spray tank. The drive motor of the power system is installed in the air cylinder through the motor base. The speed motors, fan impellers of the air-assist systems, and the atomizing turntables for test centrifugal atomizers are installed on the two output shafts of the motor, respectively. In the spray test, a test centrifugal atomizer and the fan impeller are separately driven by two output shafts of a two-speed motor, and the speed of the output shaft driving the centrifugal atomizer is steplessly adjusted by a frequency converter to obtain the required rotation speed of the atomizing turntable of the centrifugal atomizer. The fan impeller operation is controlled by a switch. The switch is on the console, and the spray center is at a height of $1395 \mathrm{~mm}$ from the ground, and the total height of the implement is $1455 \mathrm{~mm}$. Figure 1 shows the schematic of the centrifugal atomizing sprayer.

\subsection{Design and selection of basic components}

\subsubsection{Air-assisted system}

1) Axial-flow fan

One end of the two-speed motor is connected to the atomizing turntable of the atomizer, and the other is connected to the fan impeller. The fan has characteristics such as low power, high air pressure, and large air volume, and it can transport the spray droplets ejected by the atomizer in a tangential direction along the axial direction of the atomizer. The input power of the fan is
$300 \mathrm{~W}$, the speed of the impeller is $1500 \mathrm{r} / \mathrm{min}$, and the wind speed $12 \mathrm{~m}$ away from the axial direction of the fan outlet is $\geq 2 \mathrm{~m} / \mathrm{s}$; therefore, it meets the requirements of the particle size spectrum test of the centrifugal atomizer at different distances.

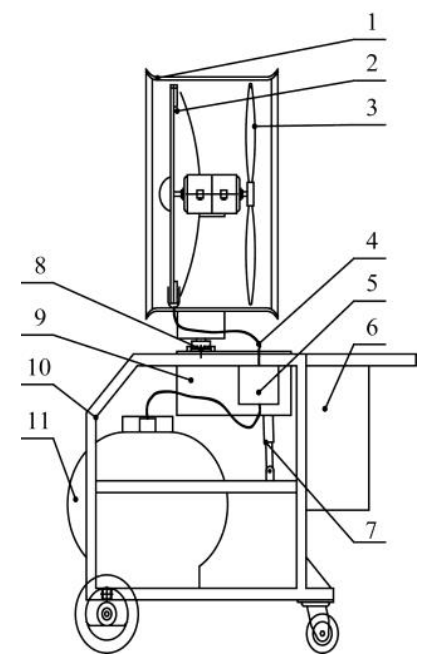

1. A ir dryer 2. Centrifugal atomizer 3.F an impeller 4.S pray liquid pipeline 5. Flow valve 6. Console 7. Vertical steering putter 8. Fan cylinder bearing housing 9.Horizontal steering motor 10. Frame 11. Spray tank

Figure 1 Schematic of centrifugal atomizing sprayer

\section{2) Power system}

The power system provides the power source for the centrifugal atomizer and fan impeller. To simplify the structure and minimize the sizes of the power system, air- assist system, and the overall size of the test bench, the power system uses a common base dual-rotor two-speed motor. The speed of the two output shafts of the motor and their operation (start and stop) can be controlled separately. The total input power of the motor is $600 \mathrm{~W}$ and the rated voltage is $220 \mathrm{~V}$. The fan impeller end is a four-pole motor with a rated power of $300 \mathrm{~W}$ and a rated speed of $1500 \mathrm{r} / \mathrm{min}$. At the end of the centrifugal atomizer is a two-pole motor with a rated power of $300 \mathrm{~W}$ and a rated speed of $3000 \mathrm{r} / \mathrm{min}$. The fan impeller and the centrifugal atomizer are driven by a dual-rotor and two-speed motor with a common base, which not only makes the machine compact, but also minimizes the size of the power, fan, and other components to achieve a small, light, and simplified tank.

\subsubsection{Variable fluid supply system}

The variable liquid supply system comprises a low-pressure small-flow submersible liquid pump, an electronically controlled pinch flow valve, and a liquid supply line. The rated power of liquid pump is $220-240 / 55 \mathrm{~V} / \mathrm{Hz}$, the rated power is $28 \mathrm{~W}$, maximum range is $2 \mathrm{~m}$, and maximum discharge is $1400 \mathrm{~L} / \mathrm{h}$. Because the spray flow of the atomizer used in this study is 0.3-0.5 $\mathrm{L} / \mathrm{min}$, it is necessary to control the flow rate of the liquid pump. However, it is difficult to achieve this under the condition of small flow rate with frequency conversion speed regulation of the liquid pump and cross sectional control of the flow channel using a solenoid valve. For fast and precise adjustments, the electronic control pinch flow valves shown in Figures 2 and 3 are used in this study to achieve a fast and precise adjustment of the liquid pump flow rate under small flow conditions. The flow adjustment range is between $0.2-1.5 \mathrm{~L} / \mathrm{min}$, and the requirement of matching the liquid supply flow needed in this study with the spraying flow of the test atomizer was satisfied. Further, the liquid supply flow rate of the complete atomization of the centrifugal atomizer was $0.26 \mathrm{~L} / \mathrm{min}$, and thus, this flow controller meets the requirements. 


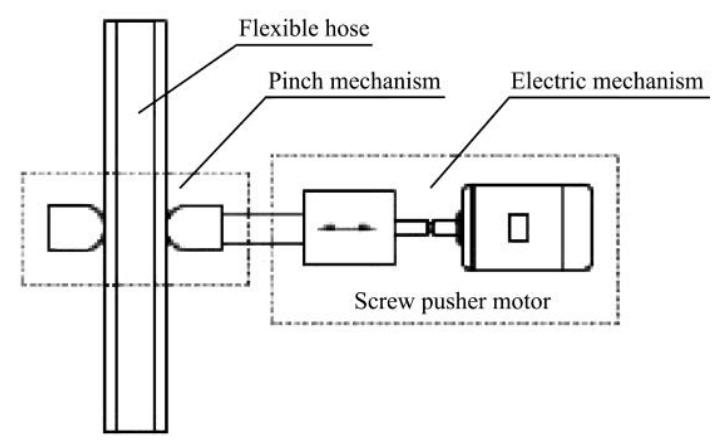

Figure 2 Mechanical principle diagram of the flow valve

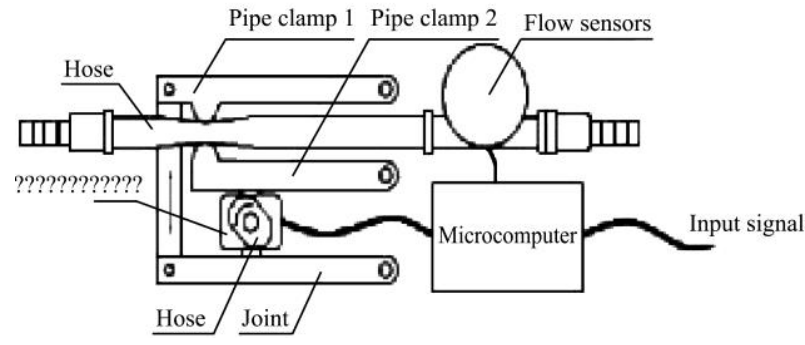

Figure 3 Control principle diagram of flow valve

\subsubsection{Spray tank and pipeline system}

The volume of the spray tank is $60 \mathrm{~L}$. According to the installation requirements of the centrifugal atomization test bench, a hole needs to be created at an appropriate position of the tank and the water outlet, and the return water pipe and circuit protection connectors should be installed as shown in Figure 4.

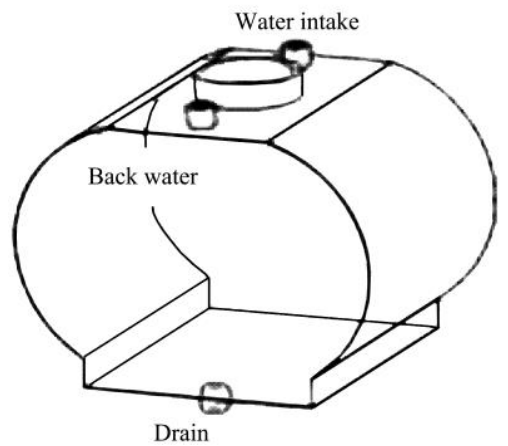

Figure 4 Spray tank

The pipeline system is composed of a liquid inlet, liquid outlet, backflow, and other pipelines. The diameter of the inlet pipe and outlet pipe is $\varphi 6 \mathrm{~mm}$, which is directly connected to the small submersible liquid pump. The spray liquid in the spray tank is sucked into the liquid pump through the inlet pipe, and then discharged by the liquid pump through the outlet pipe. The outlet pipe used for testing the centrifugal atomizer provides the spray liquid and plays the role of diversion. The diameter of the return pipe is $\varphi 16 \mathrm{~mm}$, which is directly connected to the liquid spray tank, and it quickly circulates the excess spray liquid to the liquid spray tank. Corrosion-resistant PVC hoses are used for each pipeline, and they are arranged according to the structure of the entire machine. The layout is shown in Figure 5.

\subsection{Design and selection of key components}

\subsubsection{Centrifugal Atomizer}

To study the effects of different atomizing tooth shapes, tooth numbers, and distributions on the particle size spectrum of the droplets, two designed and trial-manufactured atomizing toothed discs with different tooth shapes were used in the study. The two types of the discs are toothed discs. The centrifugal atomizing turntable adopts a three-folded structure with a diameter of $\varphi 260$ $\mathrm{mm}$ and a steplessly adjustable speed of $1500-3000 \mathrm{r} / \mathrm{min}$. There are several atomizing teeth on it.

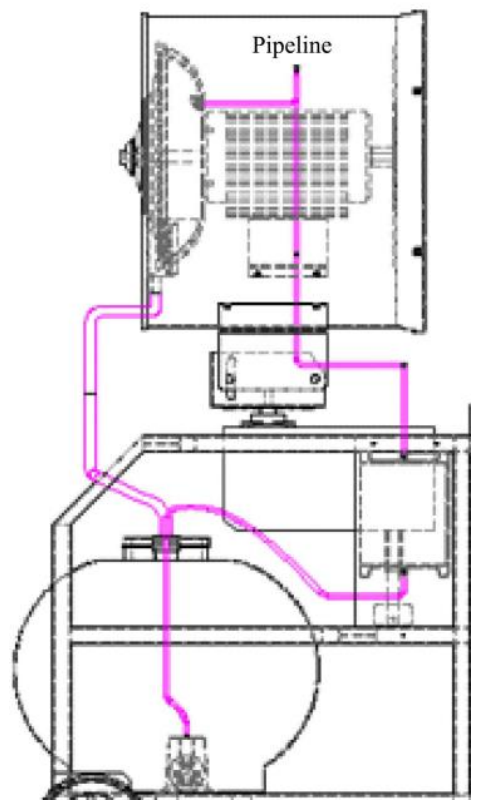

Figure 5 Pipe connection diagram of the sprayer

In the spray experiment, the liquid supply system of the centrifugal atomizer sends the chemical liquid to the center of the surface of the atomizing turntable. A liquid film is formed on the edge, and it is broken into liquid filaments after approaching or reaching the edge; then, the filaments are ejected out in a point shape. On impact with air, these filaments transform into mist droplets. The mist droplets collide with the atomizing teeth on the atomizing toothed disc and break, and they form finer mist drops.

The large diameter and three-folded structure of the centrifugal atomizing turntable allow the centrifugal atomizer to ensure a large inertial force and spray surface ${ }^{[8-13]}$, even at low speed $(<3000 \mathrm{r} / \mathrm{min})$. It can also form a uniform liquid film, which is conducive to the subsequent cracking and atomization of the medicinal solution; the multi-tooth structure of the fixed atomizing disk causes the centrifugal atomized medicinal liquid droplets to interact further, and then break into more uniform and finer droplets. Thus, the atomization quality of the centrifugal atomizer is effectively improved.

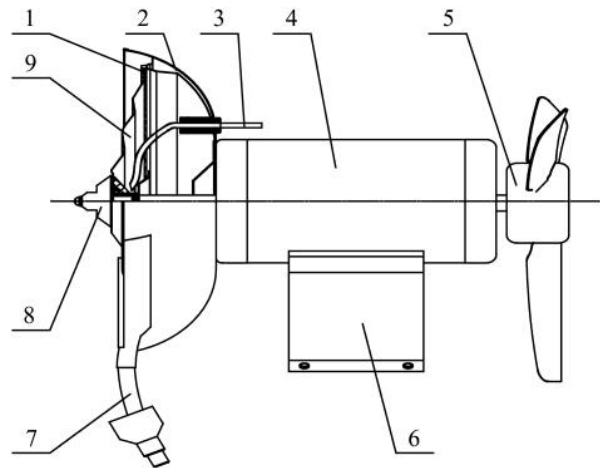

1. Fixed teeth 2. Housing 3. Inlet pipe 4. Double-speed motor 5. Fan impeller 6. Motor base 7. Chemical liquid return device 8. Fasten the screw nut 9. Centrifugal atomizing turntable

Figure 6 Centrifugal atomizer structure diagram

\subsubsection{Atomizing toothed disc}

The centrifugal atomizer atomizing tooth disc is an improvement over the original experimental research of the atomizing tooth disc. Structural parameters such as the 
cross-sectional shape, number of teeth, and distribution of the atomizing tooth are optimized to achieve fog droplets with precise and controllable droplet sizes, narrow droplet spectra, and high atomization qualities.

The design parameters of the designed atomizing toothed disc are as follows: the diameter of the atomized toothed disc is $360 \mathrm{~mm}$; 1) the tooth shape is wedge-shaped, the number of teeth is 120 ; 2) the semi-cylindrical tooth, the number of teeth is $90 ; 3$ ) the tooth shape is wedge-shaped, the number of teeth is $60 ; 4)$ the tooth shape is wedge-shaped with 45 teeth; 5) the tooth shape is wedge-shaped with 30 teeth; 6) the tooth shape is wedge-shaped with 15 teeth. These atomizing teeth with different structural parameters are shown in Figure 7.
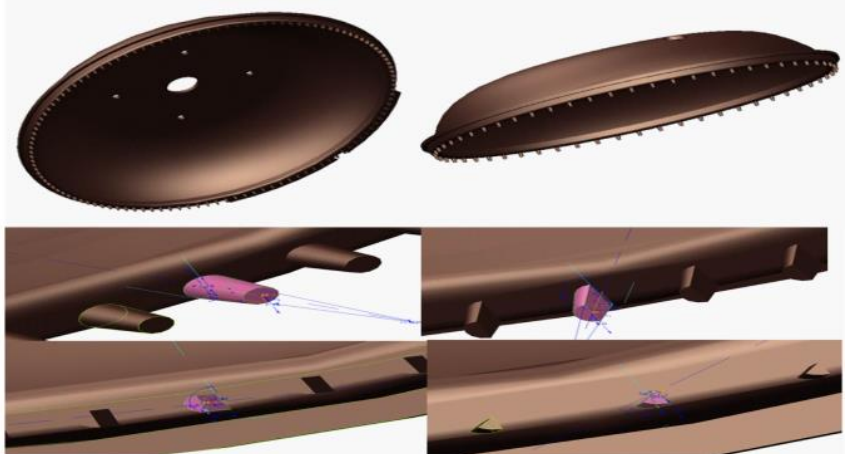

Figure 7 Three-dimensional diagram of centrifugal atomizer tooth plate with different structures

\section{Orthogonal test analysis of droplet spectrum under different structural parameters}

\subsection{Test aim}

The droplet particle spectrum analysis test is conducted to determine the droplet particle spectrum under different structural parameters such as the speed of the atomizer and the shape, number, and distribution of the atomizing teeth, and to identify the impact of different factors on the particle spectrum of the impact centrifugal atomizer (size of droplets, and particle spectrum width of fog droplets), establish a low-speed centrifugal atomizer parameter optimization design fitting formula, and obtain the structural and operating parameters of the atomizer based on optimum combination to satisfy the "bio-optimal particle size" requirements.

\subsection{Test materials}

The atomization toothed discs of several atomizers of the abovementioned design are manufactured, as shown in Figure 8.

\subsection{Test methods and steps}

The particle size analysis test for the impact-type low-speed centrifugal atomizer is used to measure the sprayed droplets under the condition of indoor still wind using a Winner 318 laser particle spectrometer (Jinan Winner Particle Instrument Co., Ltd). Before the experiment, a test centrifugal atomizer was installed on the centrifugal atomizer sprayer, and the relative position of the sprayer and the laser particle spectrometer was adjusted according to the test plan. The power line of the sprayer was connected and the optical path of the laser particle size analyzer was adjusted. During the experiment, the centrifugal atomizer was adjusted to run at a set speed from low to high through the inverter speed regulator of the sprayer. After the operation was stable, the infusion switch was turned on and the spray was adjusted to a certain working pressure of 0.3 MPa.

When the spray state was stable, the laser spectrometer laser receiver was turned on to perform dynamic droplet sampling.
Meanwhile, the computer system recorded and displayed the droplet test data and distribution curve. The sampling data was recorded in a table and saved. After sampling was finished, the test bench stopped working, and the power of the infusion switch and the test bench was cut off to ensure the safety of the droplet collection process. The centrifugal atomizer with another structural parameter was then used, and the above experimental steps were repeated. The particle size spectrum test is shown in Figure 9.

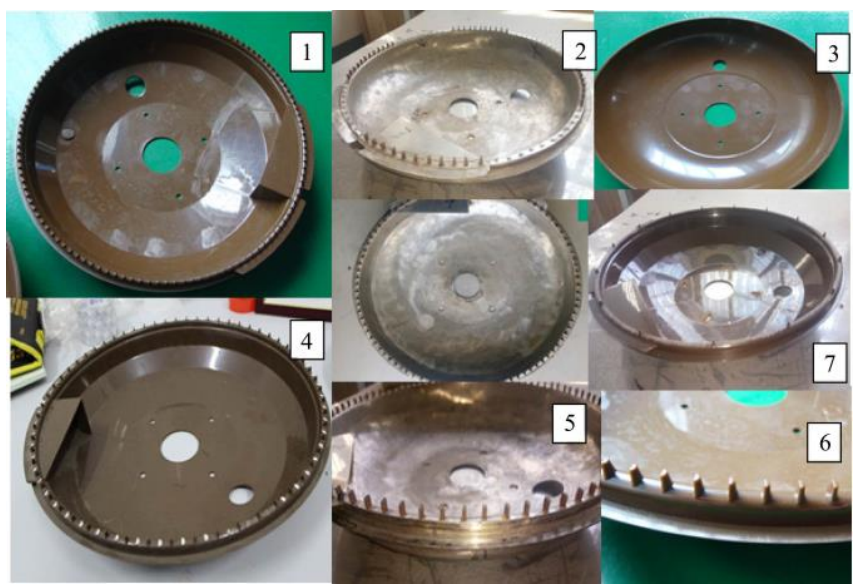

1. 120-teeth wedge-shaped atomizing toothed disc 2.45-teeth semi-cylindrical atomizing toothed disc 3. Smooth disc (without atomizer teeth) 4. 60-teeth wedge-shaped atomizing toothed disc 5. 90-teeth semi-cylindrical atomizing toothed disc 6.30-teeth wedge-shaped atomizing toothed disc 7.15-teeth wedge-shaped atomizing toothed disc.

Figure 8 Atomizing toothed disc of centrifugal atomizer with different structural parameters

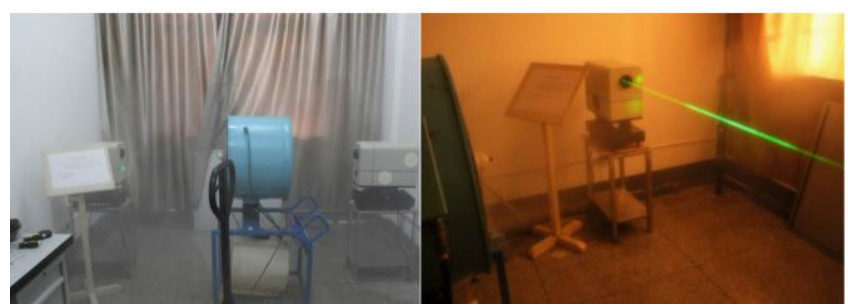

Figure 9 Droplet spectrum test

\subsection{Analysis of droplet size by orthogonal test}

Quadratic regression analysis is a scientific method for studying and processing multi-factor experiments. Through orthogonal experiment design, representative test conditions can be selected to ensure the lowest number of experiments. The corresponding test results are obtained through these few experiments, and a mathematical analysis is performed. Quadratic regression analysis was performed to obtain the optimal solution.

The volume medium diameter of the droplet and the spectral width of the droplet size are two very important indicators in droplet size analysis. In this study, the volume medium diameter of the droplet $\mathrm{D}_{50}$ and the spectral width of the droplet size $\left(D_{90}-D_{10}\right) / D_{50}$ are used. The assessment index is defined as the volume medium diameter of the droplet $Y_{1}$ and the width of the droplet spectrum $Y_{2}$. Factors with a significant effect on the droplet size are the rotating speed and the number of teeth of the atomizing disk ${ }^{[15,16]}$. Further, the rotation speed of the turntable and the number of teeth of the atomizing tooth plate were selected as independent variables, without considering the influence of the tooth shape and the distribution of the teeth on the particle size spectrum of the droplet.

In the test conditions, the center point test was repeated three times. According to the Design-Expert 8.0.6 design principle ${ }^{[22]}$, 
parameters $Y_{1}$ and $Y_{2}$ were used as the evaluation indicators. The speed $X_{1}$, the number of atomizing teeth $X_{2}$, and the response factor were also determined. The test factors and level codes are summarized in Table 1.

Table 1 Response surface test factors and levels

\begin{tabular}{ccc}
\hline & \multicolumn{2}{c}{ Factor } \\
\cline { 2 - 3 } Level & $\omega / \mathrm{r} \cdot \mathrm{min}^{-1}$ & Teeth number \\
\hline-1.41 & 1200 & 0 \\
-1 & 1838.3 & 43 \\
0 & 2100 & 60 \\
1 & 2738.3 & 103 \\
1.41 & 3000 & 120 \\
\hline
\end{tabular}

\subsection{Test results, analysis, and optimization}

\subsubsection{Orthogonal test results}

The volume medium diameter of the droplets ${ }^{[9]}$ is $\mathrm{D}_{50}$. The volume of the droplets accumulates in the ascending order during spraying. When accumulated to $50 \%$ of the total droplet volume, the corresponding droplet diameter is $\mathrm{D}_{50}$, and $\left(\mathrm{D}_{90}-\mathrm{D}_{10}\right) / \mathrm{D}_{50}$ represents a measure of the width of the droplet particle size distribution. The smaller the $\left(D_{90}-D_{10}\right) / D_{50}$, the narrower is the droplet particle spectrum, and the more uniform is the particle size distribution. The test was completed according to the abovementioned second regression response surface test design, and test data $\left(\mathrm{D}_{50}\right.$ and $\left.\left(\mathrm{D}_{90}-\mathrm{D}_{10}\right) / \mathrm{D}_{50}\right)$ under 13 test conditions were input into the Design-Expert 8.0.6 software (Table 2).

3.5.2 Establishment of regression model and significance test

According to the data in Table 2 , the secondary response surface analysis was performed using the central composite in Design-Expert 8.0.6 to establish $Y_{1}$ and $Y_{2}$. The regression model of the quadratic polynomial response surface of $X_{2}$ is given as

$$
Y_{1}=80.10-42.66 X_{1}-54.23 X_{2}+15.28 X_{1} X_{2}+17.3 X_{1}^{2}+28.87 X_{2}^{2}
$$

$$
Y_{2}=1.52-0.31 X_{1}-0.015 X_{2}-0.05 X_{1} X_{2}+0.12 X_{1}^{2}-0.32 X_{2}^{2}
$$

where, $Y_{1}$ is the volume medium diameter of the droplets, $\mu \mathrm{m} ; Y_{1}$ is the droplet spectrum width, $\mu \mathrm{m} ; X_{1}$ is the rotating speed of the atomizing turntable, and $X_{2}$ is the number of teeth of the atomizing toothed disc. The regression equation is analyzed by variance.

According to the analysis data in Table 3 , the $p$ values of the regression equation models are less than 0.01 , which indicates that the response surface model is extremely significant, and the test value of the model for the misfit term $p$ is greater than 0.05 ( $\left.p_{Y 1}=0.2613, p_{Y 2}=0.1775\right)$, which is not significant.

\section{Table 2 Quadratic regression experimental design and} response value

\begin{tabular}{ccccc}
\hline $\begin{array}{c}\text { Test } \\
\text { number }\end{array}$ & Speed $\omega$ & $\begin{array}{c}\text { Teeth } \\
\text { number }\end{array}$ & $\begin{array}{c}\text { Droplet diameter } \\
\mathrm{D}_{50} / \mu \mathrm{m}\end{array}$ & Span $\left(\mathrm{D}_{90}-\mathrm{D}_{10}\right) / \mathrm{D}_{50}$ \\
\hline 1 & 1 & 1 & 49.1 & 0.91 \\
2 & -1 & -1 & 243 & 1.62 \\
3 & 0 & 0 & 80.6 & 1.58 \\
4 & 0 & 0 & 80.4 & 1.56 \\
5 & -1.41 & 0 & 155.7 & 2.21 \\
6 & -1 & 1 & 105.1 & 1.63 \\
7 & 0 & 1.41 & 58.4 & 0.89 \\
8 & 1.41 & 0 & 60.1 & 1.42 \\
9 & 1 & -1 & 120.9 & 1.10 \\
10 & 0 & 0 & 79.6 & 1.57 \\
11 & 0 & -1.41 & 213.6 & 0.92 \\
12 & 0 & 0 & 78.3 & 1.55 \\
13 & 0 & 0 & 81.2 & 1.56 \\
\hline
\end{tabular}

\begin{tabular}{|c|c|c|c|c|c|c|c|c|}
\hline \multirow{2}{*}{ Source } & \multicolumn{4}{|c|}{$\mathrm{D}_{50} / \mu \mathrm{m}$} & \multicolumn{4}{|c|}{$\left(\mathrm{D}_{90}-\mathrm{D}_{10}\right) / \mathrm{D}_{50} / \mu \mathrm{m}$} \\
\hline & Sum of squares & Degree of freedom & F value & $p$ value & Sum of squares & Degree of freedom & $F$ value & $p$ value \\
\hline Model & 343.68 & 5 & 11.69 & $<0.0001 * *$ & 1.72 & 5 & 3.66 & $<0.0001 * *$ \\
\hline$X_{1}$ & 73.14 & 1 & 12.44 & $<0.0001 * *$ & 0.78 & 1 & 8.28 & $0.024 *$ \\
\hline$X_{2}$ & 196.52 & 1 & 33.42 & $<0.0001 * *$ & 0.00 & 1 & 0.02 & $<0.0001 * *$ \\
\hline$X_{1} X_{2}$ & 9.42 & 1 & 1.60 & $<0.0001^{*}$ & 0.01 & 1 & 0.11 & $<0.0001 * *$ \\
\hline$X_{1}^{2}$ & 2.16 & 1 & 0.37 & $0.046^{*}$ & 0.11 & 1 & 1.15 & $0.032 *$ \\
\hline$X_{2}^{2}$ & 64.40 & 1 & 10.95 & $0.013^{*}$ & 0.73 & 1 & 7.81 & $0.027 *$ \\
\hline Residual & 41.16 & 7 & 3.61 & 0.2613 & 0.66 & 7 & \multirow{4}{*}{2.75} & \multirow{4}{*}{0.1775} \\
\hline Lack of fit & 41.04 & 3 & & & 0.66 & 3 & & \\
\hline Pure error & 0.15 & 4 & & & 0.00 & 4 & & \\
\hline Cor total & 384.84 & 12 & & & 2.38 & 12 & & \\
\hline
\end{tabular}

Table 3 Regression equation ANOVA

Note: $* * p<0.01$ (highly significant); ${ }^{*} p<0.05$ (significant); $X_{1}$-Atomizing turntable speed; $X_{2}$-Atomizing gear tooth number

The test value of the mismatch term $P$ indicates that the model is in good agreement with the data. The determination coefficients $R^{2}$ of the evaluation indexes $Y_{1}$ and $Y_{2}$ are 0.893 and 0.886 , respectively, indicating that the regression model fits well.

Based on these results, the model can well describe these two response variables, and the prediction of the response surface model is reasonable, which can be used to optimize the structural and working parameters of the centrifugal atomizer.

3.5.3 Analysis of the interaction between the structural and working parameters of the atomizer

According to the analysis results of the regression equation, the response surface was used to investigate the influence of each parameter on the evaluation index. This study examined the effect of the interaction between the atomizer structure parameters and the working parameters on $\mathrm{D}_{50}$ and particle width $\mathrm{D}_{10} / \mathrm{D}_{50}$ using two response values to obtain the optimal combination of the structural parameters and working parameters of the atomizer.

Figure 10 indicates that, the larger the number of teeth and the rotation speed of the atomizing toothed disc, the smaller is the volume medium diameter of the droplet. The analysis shows that when the number of teeth of the atomizing sprocket is large, spray liquid is ejected by the turntable and the atomizing teeth are more fully impacted, and the spray liquid is more fully atomized; therefore, the mist droplets are finer and the volume of the droplets is smaller. The value of the diameter is smaller, and under the same structural parameters, the greater the rotation speed of the atomizing turntable, the greater is the centrifugal force of the atomizing turntable, and therefore, the droplets thrown out by the 
atomizing turntable have a larger initial kinetic energy and impact the atomization. The force of the tooth is higher, and therefore, the secondary atomization is more complete. Thus, under the same structural parameters, the higher the rotation speed, the finer are the droplets that are generated, and the smaller is the volume medium diameter of the droplet. Further, Figure 10 shows that when the number of atomizing teeth is 0 , the volume medium diameter of the droplet is larger, and the slope of the corresponding secondary response surface is steeper than before. Therefore, the volume medium diameter of the droplet generated by the low-speed centrifugal atomizer without atomizing teeth is more significantly affected by the rotation speed of the atomizing turntable.

The response surface curve of interaction factor to droplet particle spectrum width value is shown in Figure 11. The larger the atomizer rotating speed of the atomizer with the same number of teeth, the narrower is the droplet particle spectrum width, i.e., the droplet particle size distribution is more uniform. Under the condition of the same rotating speed of the atomizing turntable, for a higher number of teeth of the atomizing toothed disc, the droplet particle spectrum first widens and then narrows, and the secondary response surface is saddle-shaped, without the median diameter and droplet particle volume extreme values of spectral width.
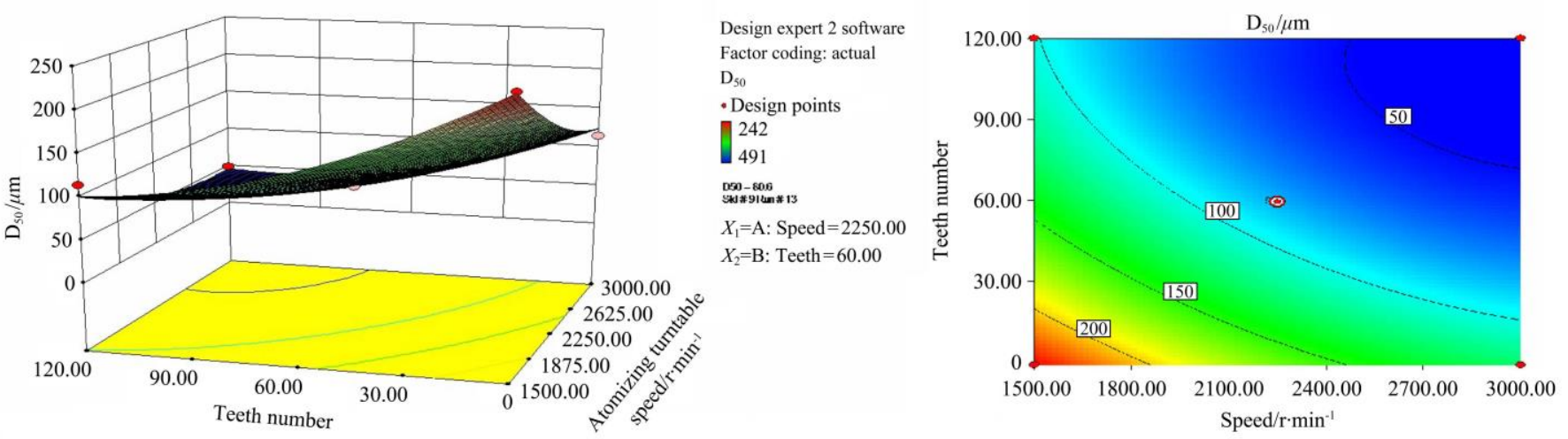

Figure 10 Interaction effects on volume medium diameter of droplet
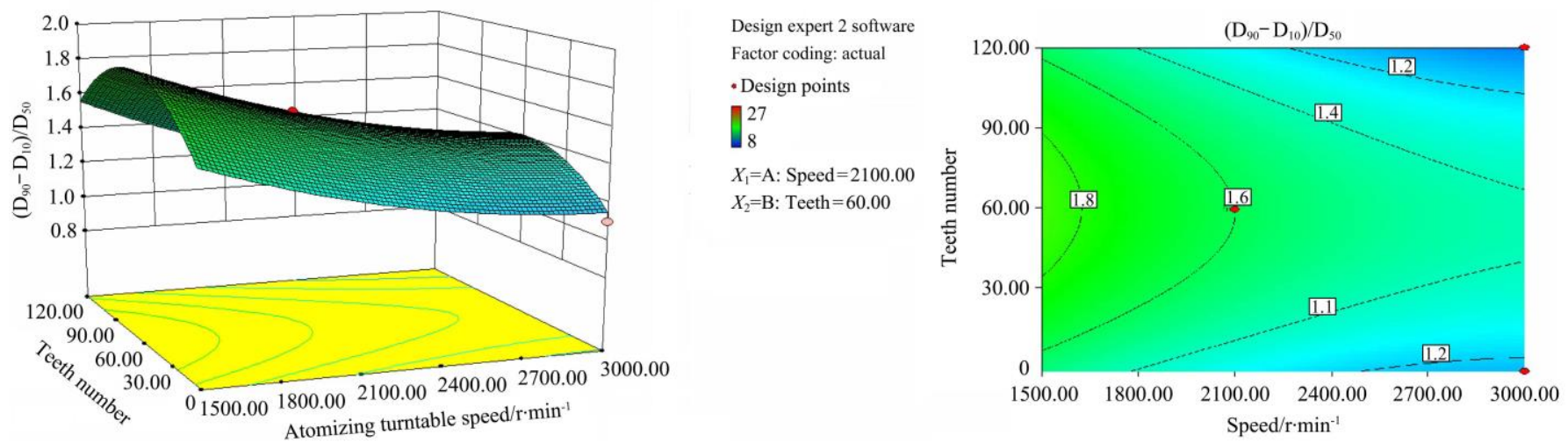

Figure 11 Interaction effects on the droplet spectrum span

3.5.4 Optimization of atomizer structure parameters and working parameters

According to the biological optimal particle size theory, an optimal particle size relationship exists between the pesticide efficacy and droplet size ${ }^{[9]}$. Based on relevant research ${ }^{[1]}$, the droplet size for controlling small insects in flight is found to be within $30-50 \mu \mathrm{m}, \mathrm{D}_{50}=40 \mu \mathrm{m}$; the droplet size for reptile larvae and spray fungicides is between $30-150 \mu \mathrm{m}, \mathrm{D}_{50}=90 \mu \mathrm{m}$; and when the size of the spray droplets is between 100-300 $\mu \mathrm{m}$, the intermediate value of $\mathrm{D}_{50}=200 \mu \mathrm{m}$ is considered. According to the requirements of this optimal particle size theory on the droplet size combined with the atomization model proposed in this study, a droplet size of $Y_{1}=40 \mu \mathrm{m}$ was used for the control of small flying pests; $Y_{1}=90 \mu \mathrm{m}$ was used for the control of reptile larvae and spraying fungicide, and $Y_{1}=200 \mu \mathrm{m}$ was considered for the control of crops and grasses. In MATLAB, for $X_{1}$ and $X_{2}$ in the interval $[-\sqrt{2}, \sqrt{2}]$, the minimum value of $Y_{2}$ was determined.

When $Y_{1}=40 \mu \mathrm{m}, X_{1}=0.715$ and $X_{2}=0.802$, i.e., the rotation speed $\omega=2588.5 \mathrm{r} / \mathrm{min}$, and the number of teeth $n=94.5$, the minimum value of $Y_{2}=1.113 \mu \mathrm{m}$. When $n=95$, and $\omega=2600 \mathrm{r} / \mathrm{min}$.

When $Y_{1}=90 \mu \mathrm{m}, X_{1}=-0.726$, and $X_{2}=0.581$, i.e., $\omega=$ $1910.0 \mathrm{r} / \mathrm{min}$, and $n=84.9$, the minimum value of $Y_{2}=1.792$. When the atomized tooth plate is rounded, $n=85$, and $\omega=2000 \mathrm{r} / \mathrm{min}$.

When $Y_{1}=200 \mu \mathrm{m}, X_{1}=0.012, X_{2}=-1.396$, i.e., $\omega=2107.6 \mathrm{r} / \mathrm{min}$ and $n=41.5$, the minimum value of $Y_{2}=0.914$. When $n=42$, $\omega=2100 \mathrm{r} / \mathrm{min}$.

\section{Conclusions}

In this study, an impact-type centrifugal atomizing sprayer and its key and basic components were designed. Further, the secondary response surface regression analysis of the different structural and working parameters of the atomizer was performed to establish the volume diameter of the droplet. The main conclusions can be drawn as follows:

1) With variance and response surface analyses, the significance of the factors affecting the droplet size was obtained in a descending order: rotating speed of the atomizing turntable, the number of teeth of the atomizing gear, the tooth shape of the atomizing teeth.

2) Design-Expert8.5 was used to perform quadratic response surface regression analysis on each influencing factor. The $p$ values of the regression equation models indicated that the response surface model is extremely significant, and the model's misfit test value and the insignificant test value $p$ of the misfit term 
indicated that the model is in good agreement with the data. Further, the evaluation coefficients of the droplet median diameter $Y_{1}$, and droplet width $Y_{2}$ are 0.893 and 0.886 , respectively, which indicate the regression model has a good fit. Based on this, the model can describe these two response variables very well, and the prediction of the response surface model is reasonable, which can be used to optimize the structural and working parameters of the centrifugal atomizer.

3) Through the response surface analysis of the interaction effect of the structural parameters and working parameters of the atomizer on the volume medium diameter of the droplet and the spectrum width of the droplet droplets, the model for predicting the droplet spectrum of the atomizer was established, and the optimal design proposal was obtained.

\section{Acknowledgements}

This work was financially supported by National Key Research and Development Program of China (2017YFD0200303), China Agriculture Research System (CARS-25).

\section{[References]}

[1] Yuan H. Pesticide use technical guide. Chemical Industry Press, 2011; pp.168-169. (in Chinese)

[2] Zhao G, Liu J. Experimental research on the performance of two kinds of centrifugal spray nozzles. China Agricultural Mechanization, 2005; 2: 69-71. (in Chinese).

[3] Zhou H, Yang X, Yan H, Zhang Z. Research and development of high ground clearance precision variable plant protection machinery. Agricultural Machinery, 2006; 9B: 35-36. (in Chinese)

[4] Zhou H, Yang X, Yan H, Xu S. Test of rotary disc centrifugal nozzle of wind wheel. Journal of Agricultural Machinery, 2008; 10: 89-92.

[5] Liu J. The study about appliance and technology of Cannon rotary-atomizing long-shot air-assisted spraying. Master dissertation. Yangling: Northwest A\&F University, 2004; 65p. (in Chinese)

[6] Peng J. The numerical simulation study of the inner flow field in the air-assisted hydraulic ultra-low volume sprayer device. Master dissertation. Wuhan: Wuhan University of Technology, 2006; 65p. (in Chinese)

[7] Zhang X, Gong Y, Chen X, Liu D, Wang G. Research and application of controlled spraying intelligent pesticide application technology in facility agriculture. Journal of Chinese Agricultural Mechanization, 2019; 40(11): 49-54.

[8] Yang F, Xue X, Cai C, Zhou Q, Sun Z. Atomization performance test and influencing factors of special aviation centrifugal nozzles. Journal of Agricultural Machinery, 2019; 50(9): 96-104.

[9] $\mathrm{Wu} \mathrm{J}$, Zhang R, Xu Y, Zhang Z, Zu J. Experimental research and numerical simulation of atomization characteristics of centrifugal nozzles. Fire Science and Technology, 2017; 36(12): 1685-1687

[10] Yuan H, Wang G. The relationship between fog droplet size and coverage density and pesticide control effect. Journal of Plant Protection, 2015; 6: 9-16.

[11] Brown R B, Sidahmed M M. Simulation of spray dispersal and deposition from a forestry airblast sprayer part II: droplet trajectory model. Transactions of the ASAE, 2001; 44(1): 11-17.

[12] Beck J C, Watkins A P. The droplet number moments approach to spray modelling: the development of heat and mass transfer sub-models. International Journal of Heat and Fluid Flow, 2003; 24(2): 242-259.

[13] Chapple A C, Taylor R A J, Hall F R. The transformation of spatially determined drop sizes to their temporal equivalents for agricultural sprays. Journal of Agricultural Engineering Research, 1995; 60(1): 49-56.

[14] Cunningham G P, Harden J. Reducing spray volumes applied to mature citrus trees. Crop Protection, 1998; 17(4): 289-292.

[15] Cross P, Edwards-Jones G. Variation in pesticide hazard from arable crop production in Great Britain from 1992 to 2002: Pesticide risk indices and policy analysis. Crop Protection, 2006; 25(10): 1101-1108.

[16] Dekeyser D, Foque D, Duga AT, Verboven P, Hendrickx N, Nuyttens D. Spray deposition assessment using different application techniques in artificial orchard trees. Crop Protection, 2014; 64: 187-97.

[17] Ebert T A, Downer R A. A different look at experiments on pesticide distribution. Crop Protection, 2006; 25(4): 299-309.

[18] Katul G G, Mahrt L, Poggi D, Sanz C. One-and two-equation models fo canopy turbulence. Boundary-Layer Meteorology, 2004; 113(1): 81-109.

[19] Matthews G A, Thomas N. Working towards more efficient application of pesticides. Pest Management Science, 2000; 56(11): 974-976.

[20] Phattaralerphong J, Sathornkich J, Sinoquet H. A photographic gap fraction method for estimating leaf area of isolated trees: assessment with 3D digitized plants. Tree Physiology, 2006; 26(9): 1123-1136.

[21] Tokekar P, Vander Hook J, Mulla D, Isler V. Sensor planning for a symbiotic UAV and UGV system for precision agriculture. IEEE Transactions on Robotics, 2016; 32(6): 1498-1511.

[22] Li H, He X, Zhong C. Multi-factor response surface model of the effect of charged fog droplet deposition. High Voltage Technology, 2007; 33(2): 32-36.

[23] Zhu A. Research on formation and distribution of particles in centrifugal atomized plasma spray. China Surface Engineering, 2006; 19(4): 32-39. 